\title{
ROBUST SYNCHRONISATION OF UNCERTAIN FRACTIONAL-ORDER CHAOTIC UNIFIED SYSTEMS
}

\author{
Naeimadeen Noghredani and Saeed Balochian ${ }^{\#}$ \\ Department of Electrical Engineering, Gonabad Branch, Islamic Azad University, Gonabad / Khorasan-e-Razavi, 96916-29, IRAN \\ naeim-noghrehdani@ hotmail.com, Saeed.balochian@gmail.com \\ \# Corresponding author
}

Communicated by Isaak Rashal

\begin{abstract}
Fractional-order chaotic unified systems include a variety of fractional-order chaotic systems such as Chen, Lorenz, Lu, Liu, and financial systems. This paper describes a sliding mode controller for synchronisation of fractional-order chaotic unified systems in the presence of uncertainties and external disturbances, and affirms the stability of the controller (which is composed of error dynamics). Moreover, the synchronisation of two separate fractional-order chaotic systems is studied. For this aim, fractional integral sliding surface is defined. Then the sliding mode control rule for stability of error dynamic is presented based on the Lyapunov stability theorem. Simulation results, obtained by using MATLAB, show that the proposed sliding mode has employed an appropriate approach against uncertainties and to reduce the chattering phenomenon that often occurs with sliding mode controllers.
\end{abstract}

Key words: fractional-order chaotic unified systems, uncertainty, chaos, synchronisation.

\section{INTRODUCTION}

The broad field of chaos theory has been among the most interesting issues researchers have studied in recent decades. Concepts related to chaos theory and its related disciplines are employed in different fields, including medicine (Sarbaz et al., 2012; Aghababa and Borjkhani 2014; Provata et al., 2012), economics (Pan et al., 2012; Airaudo and Zanna, 2012), functioning of laser diodes (Banerjee et al., 2012; Gao, 2012), and mathematics (Hosseinalipour, 2013; Kupka, 2014). The control of chaos-related phenomena has attracted wide attention from many different kinds of researchers.

Although the idea of fractional-order operators has a history as long as that of integer-order operators, interest in this field is expanding due to an increasing amount of attention from scientists and mathematicians. In recent decades, fractional-order operators have been the driving force behind an increasing number of investigations. With the development of studies in this area, practical and theoretical investigations into the application of fractional-order operators in engineering sciences have now become widespread in the academic community (Padula and Visioli, 2014; Pakzad et al., 2013; Tripathy et al., 2015a; Tripathy et al., 2015b). For example, fractional-order calculations have been applied in mechanical and electrical engineering, biology, economics, and mathematics, among other fields (Her- nandez et al., 2014; Wang and Li, 2014; Cortes and Elejabarrieta, 2007).

A chaotic system is a highly complex, dynamic nonlinear system. The important and salient characteristics of chaotic systems include their extreme sensitivity to initial conditions, making the synchronisation of chaotic systems vital. The rapid increase in interest in fractional-order chaotic systems has manifested in investigations into the chaotic behavior of fractional-order horizontal platform systems (Aghababa, 2014) and in the proliferation of other published articles on these systems (Yin et al., 2013; Li and Chen, 2014; Li and Tong, 2013).

During the past two decades, the control and synchronisation of fractional-order and integer-order chaotic systems have largely attracted scientists and researchers due to their potential applications in secure communications, biological systems, medicine, and other fields. For example, an active-control technique has been provided for the identical and non-identical synchronisation of fractional-order chaotic systems (Srivastava et al., 2014). In a different application, function-projective synchronisations (FPS) of identical and non-identical modified finance systems (MFS) and the Shimizu-Morioka system (S-MS) have been studied via active control technique (Kareem et al., 2012). Fast projective synchronisation of fractional-order chaotic and reverse chaotic systems with its application to an affine cipher using date of birth (DOB) have also been reviewed (Muthukumar 
et al., 2015). Specifically related to our paper, an adaptive sliding mode controller with a robust synchronisation approach has been proposed for fractional-order chaotic systems in the presence of uncertainty (Zhang and Yan, 2014). A new controller for the master-slave synchronisation of a chaotic Lur'e system has been provided by Xiao et al. (2014). In addition, a discrete-time sliding mode controller has been suggested for the master-slave synchronisation of chaotic systems in the presence of uncertainties (Pai, 2014). Faieghi and Delavari studied chaotic synchronisation of the Genesio-Tesi system utilising either an active-control or a sliding-mode strategy (Faieghi and Delavari, 2012).

In this paper, a set of fractional-order chaotic systems with uncertainty and external noise is considered, which can include a variety of fractional-order chaotic systems such as Chen, Lorenz, Lu, Liu, and financial. A fractional-order sliding mode controller is proposed based on the system's error dynamics, leading to the control and synchronisation of fractional-order uncertain chaotic systems in the presence of external noise. In addition, asymptotic stability of the proposed controller is investigated. The simulation results clearly demonstrate the effectiveness of the proposed method in the elimination of uncertainty and the quicker convergence response from the system.

\section{PRELIMINARIES}

The derivative operator-integrator is characterised by ${ }_{a} D_{t}^{q}$, a combination of differential-integral operators used in the calculations. This operator symbol is defined as follows:

${ }_{a} D_{t}^{q}\left\{\begin{array}{cc}\frac{d^{q}}{d t^{q}} & q>0 \\ 1 & q=0 \\ \int_{q}^{t}(d t)^{-q} & q<0\end{array}\right.$

where $q$ is the fractional order. There are various definitions for fractional derivative and integral factors; the most common are the Grunwald-Letnikov derivative, the RiemannLiouville fractional derivative, and the Caputo derivative. For the remainder of this paper the Riemann-Liouville (RL) definition of fractional derivative is used. The RL fractional derivative in the order of $q$ is explained below (Monje et al, 2010):

$$
\begin{aligned}
{ }_{a} D_{t}^{q} f(t)=D^{q} f(t)= & \frac{d^{q} f(t)}{d t^{q}}= \\
& =\frac{1}{\Gamma(m-q)} \frac{d^{m}}{d t^{m}} \int_{0}^{t} \frac{f(\tau)}{(t-\tau)^{q+m-1}} d \tau
\end{aligned}
$$

where $m$ is the first integer that is not less than $q$, i.e. $m-1 \leq q<m$, and $\Gamma$ (.) is the well-known Euler's gamma function:

$\Gamma(p)=\int_{0}^{\infty} t^{p-1} e^{-t} d t ; \Gamma(p+1)=p \Gamma(p)$
Lemma 1 (Matignon, 1996). The following autonomous system:

$\frac{d^{q} x}{d t^{q}}=A x, x(0)=x_{0}$

with $0<q<1, x \in R^{n}$, and $A \in R^{n \times n}$, is asymptotically stable if and only if

$|\arg (\operatorname{eig}(A))|>\frac{q \pi}{2}$.

In this case, each component of these states decays toward 0 like $t^{-q}$. Also, this system is stable if and only if $|\arg (\operatorname{eig}(A))| \geq \frac{q \pi}{2}$ and those critical eigenvalues that satisfy $|\arg (\operatorname{eig}(A))|=\frac{q \pi}{2}$ have a geometric multiplicity of one.

\section{SYSTEM DESCRIPTION}

In this paper, we consider chaos synchronisation for the unified fractional-order chaotic system (Chai, 2013). The mathematical model for the unified fractional-order chaotic system is given by

$$
\left\{\begin{array}{l}
\frac{d^{q} x_{1}}{d t^{q}}=(15 \alpha+10)\left(x_{2}-x_{1}\right) \\
\frac{d^{q} x_{2}}{d t^{q}}=(28-35 \alpha) x_{1}+(29 \alpha-1) x_{2}-x_{1} x_{3} \\
\frac{d^{q} x_{3}}{d t^{q}}=x_{1} x_{2}-\frac{8+\alpha}{3} x_{3}
\end{array}\right.
$$

where $x_{1}, x_{2}, x_{3}$ are state variables and parameter $\alpha \in[0,1]$. In fact, the aforementioned chaotic system has chaotic behavior for $\alpha \in[0,1]$. It is called a general Lorenz system when $\alpha \in[0,0.8]$; it becomes a general Lu system when $\alpha=0.8$, and a general Chen system at $\alpha \in[0.8,1]$.

If we consider System (5) to be the master, the slave system would be as follows

$$
\left\{\begin{array}{l}
\frac{d^{q} y_{1}}{d t^{q}}=(25 \alpha+10)\left(y_{2}-y_{1}\right) \\
\frac{d^{q} y_{2}}{d t^{q}}=(28-35 \alpha) y_{1}+(29 \alpha-1) y_{2}-y_{1} y_{3} \\
\frac{d^{q} y_{3}}{d t^{q}}=y_{1} y_{2}-\frac{8+\alpha}{3} y_{3}
\end{array}\right.
$$

where $y_{1}, y_{2}, y_{3}$ are state variables and $q$ consists of fractional orders that satisfy $0<q_{i}<1$. For added convenience, we rewrite the master and slave system as below.

$$
\begin{aligned}
& D^{q} X(t)=A X(t)+B g(X) \\
& D^{q} Y(t)=A Y(t)+B g(Y)
\end{aligned}
$$

where 


$$
\begin{aligned}
& A=\left[\begin{array}{ccc}
-(25 \alpha+10) & (25 \alpha+10) & 0 \\
(28-35 \alpha) & (29 \alpha-1) & 0 \\
0 & 0 & -\frac{8+\alpha}{3}
\end{array}\right], B=\left[\begin{array}{ll}
0 & 0 \\
1 & 0 \\
0 & 1
\end{array}\right], \\
& g(X)=\left[\begin{array}{c}
-x_{1} x_{3} \\
x_{1} x_{2}
\end{array}\right], g(Y)=\left[\begin{array}{c}
-y_{1} y_{3} \\
y_{1} y_{2}
\end{array}\right]
\end{aligned}
$$

To control and synchronise unified fractional-order chaotic systems, the control input $U(t)=\left[u_{1}(t), u_{2}(t), u_{3}(t)\right]$ is added to the slave system:

$D^{q} Y(t)=A Y(t)+B g(y)+U(t)$

The aim of adding the sliding mode controller $U(t)$ to System (8) is the minimisation of synchronisation error; i.e., $\lim _{t \rightarrow \infty} e(t)=0$. In this formulation, $e(t)=y(t)-x(t)$.

\section{SYNCHRONISATION VIA FRACTIONAL-ORDER SLIDING MODE CONTROLLER}

A sliding mode controller usually is implemented with two objectives. First, it allows definition of the vector of the sliding surface. Second, the control signal to reach the sliding surface can be determined. In this article, a fractionalorder sliding surface is proposed that guarantees the synchronisation of both master and slave systems.

\section{Design of switching surface}

The sliding fraction-integer integral surface is as follows:

$S(t)=D^{q-1} E(t)-\int_{0}^{t}(A+K) E(\tau) d \tau$

where $D^{q-1} E(t)=D^{q-1} Y(t)-D^{q-1} X(t), \quad S=\left[S_{1}, S_{2}, S_{3}\right]$, and $K \in R^{3 \times 3}$ is a designed parameter matrix. In the sliding mode, the sliding surface and its derivative must satisfy:

$s(t)=0, \quad \dot{s}(t)=0$

This means that:

$$
\begin{gathered}
\dot{S}(t)=D^{q} E(t)-(A+K) E(t)=A Y(t)+B g(Y)+U(t)-A X(t)- \\
-B g(X)-A E(t)-K E(t)=B g(Y)-B g(X)+U(t)-K E(t)(12)
\end{gathered}
$$

Thus, for satisfaction of Equation (11), $U_{e q}$ will be as follows:

$U_{e q}(t)=K E(t)+B g(X)-B g(Y)$

To satisfy the sliding condition, the reaching law can be chosen as

$U_{r}(t)=-(r S+\rho \operatorname{sign}(S))$

where

$\operatorname{sign}(s)=\left\{\begin{array}{cc}1 & s>0 \\ 0 & s=0 \\ -1 & s<0\end{array}\right.$
In addition, $r$ and $\rho$ stand for non-negative constant or control gains.

Using Equations (13) and (14), the control rule is defined as follows:

$$
\begin{aligned}
U(t)=U_{e q}(t)+U_{r}(t)=K E(t)+B g(X) & -B g(Y)- \\
& -(r S+\rho \operatorname{sign}(S))
\end{aligned}
$$

Theorem 1. The Control law (16) based on the defined sliding surface (10) synchronises the trajectories of systems (7) and (9) and within $r>0$ and $\rho>0$ gains, dependent on the appropriate selection of matrix $K$ to be like $|\arg (e i g(A+K))|>\frac{q \pi}{2}$

Proof. By adopting the Lyapunov function $V=\frac{1}{2} S^{T} S$, it is guaranteed that the state jumps at the switching instants.

$$
\begin{array}{r}
\dot{V}=S^{T} \dot{S}=S^{T}\left[D^{q} E(t)-(A+K) E(t)\right]=S^{T}[A E(t)+B g(Y)- \\
-B g(X)+K E(t)+B g(X)-B g(Y)-r S-\rho s i g n(S)-A E(t)- \\
-K E(t)]=-r\|S\|^{2}-\rho\|S\|<0 \quad(17)
\end{array}
$$

Since the Lyapunov function is positive and its derivation is negative, the asymptotic stability of the controller is achieved only when the controller's gains are selected appropriately, i.e. $r>0$ and $\rho>0$.

Design of sliding mode controller for synchronisation of uncertainty systems

Now, consider the System (5) in the presence of uncertainty and external noise:

$$
\left\{\begin{array}{l}
\frac{d^{q} x_{1}}{d t^{q}}=(25 \alpha+10)\left(x_{2}-x_{1}\right)+\Delta f_{1}\left(x_{1}, x_{2}, x_{3}\right)+d_{1}(t) \\
\frac{d^{q} x_{1}}{d t^{q}}=(28-35 \alpha) x_{1}+(29 \alpha-1) x_{2}-x_{1} x_{3}+ \\
+\Delta f_{2}\left(x_{1}, x_{2}, x_{3}\right)+d_{2}(t) \\
\frac{d^{q} x_{3}}{d t^{q}}=x_{1} x_{2}-\frac{8+\alpha}{3} x_{3}+\Delta f_{3}\left(x_{1}, x_{2}, x_{3}\right)+d_{3}(t)
\end{array}\right.
$$

where $\Delta f_{i}\left(x_{1}, x_{2}, x_{3}\right), i=1,2,3$, are the parameter uncertainties, and $d_{i}(t), i=1,2,3$ are external noise perturbations. For convenience, we rewrite System (18) as below.

$D^{q} X(t)=A X(t)+B g(X)+H(X, t)$

where $\Delta f\left(x_{1}, x_{2}, x_{3}\right)=\left[\Delta f_{1}\left(x_{1}, x_{2}, x_{3}\right), \quad \Delta f_{2}\left(x_{1}, x_{2}, x_{3}\right)\right.$, $\left.\Delta f_{3}\left(x_{1}, x_{2}, x_{3}\right)\right]^{T}, d(t)=\left[d_{1}(t), d_{2}(t), d_{3}(t)\right]^{T}$ and matrices $A$, $B$ and function $g($.$) are defined as in System (7) and$ $H(X, t)=\Delta f\left(x_{1}, x_{2}, x_{3}\right)+d(t)$.

In addition, considering that the uncertainties and external noises are finite, the upper bound of $H(X, t)$ is assumed to be equal to $\gamma_{1}$. i.e. $\|H(X, t)\| \leq \gamma_{1}$.

When uncertainty, noise, and control signal are added to the slave system, we have: 


$$
\begin{aligned}
& \frac{d^{q} y_{1}}{d t^{q}}=(25 \alpha+10)\left(y_{2}-y_{1}\right)+\Delta f_{4}\left(y_{1}, y_{2}, y_{3}\right)+d_{4}(t)+u_{1}(t) \\
& \begin{aligned}
& \frac{d^{q} y_{2}}{d t^{q}}=(28-35 \alpha) y_{1}+(29 \alpha-1) y_{2}-y_{1} y_{3}+ \\
&+\Delta f_{5}\left(y_{1}, y_{2}, y_{3}\right)+d_{5}(t)+u_{2}(t) \quad(20) \\
& \frac{d^{q} y_{3}}{d t^{q}}=y_{1} y_{2}-\frac{8+\alpha}{3} y_{3}+\Delta f_{6}\left(y_{1}, y_{2}, y_{3}\right)+d_{6}(t)+u_{3}(t)
\end{aligned}
\end{aligned}
$$

where $\Delta f_{i}\left(y_{1}, y_{2}, y_{3}\right), i=4,5,6$, are the parameter uncertainties and $d_{i}(t), i=4,5,6$ are external noise perturbations. With rewriting of System (20) as shown below, we will have:

$D^{q} Y(t)=A Y(t)+B g(Y)+H(Y, t)+U(t)$

where $\Delta f\left(y_{1}, y_{2}, y_{3}\right)=\left[\Delta f_{4}\left(y_{1}, y_{2}, y_{3}\right), \quad \Delta f_{5}\left(y_{1}, y_{2}, y_{3}\right)\right.$, $\left.\Delta f_{6}\left(y_{1}, y_{2}, y_{3}\right)\right]^{T}, \quad d(t)=\left[d_{4}(t), d_{5}(t), d_{6}(t)\right]^{T}, \quad U(t)=$ $\left[u_{1}(t), u_{2}(t), u_{3}(t)\right]$, and matrices $A, B$ and function $g($.$) are$ defined as in System (8) and $H(Y, t)=\Delta f\left(y_{1}, y_{2}, y_{3}\right)+d(t)$. In addition, we have assumed that the upper bound of $H(Y, t)$ is equal to, i.e. $\|H(Y, t)\| \leq \gamma_{2}$. The designed sliding mode controller based on sliding surface Equation (10) is presented as:

$$
\begin{aligned}
U(t)=K E(t)+B g(X)-B g(Y)-(r S & +\rho_{1} \gamma_{1} \operatorname{sign}(S)+ \\
& \left.+\rho_{2} \gamma_{2} \operatorname{sign}(S)\right)
\end{aligned}
$$

Similar to Theorem 1, we can design a sliding mode controller for asymptotic stability of the error trajectories between the master and slave systems.

Theorem 2. Consider the master-slave configuration of a fractional-order chaotic unified system in the presence of uncertainty and external noise in Equations (19) and (21). With proper adoption of the control law in Eq. (22), where $r>0, \rho_{1}>-1$ and $\rho_{1}>1$, as well as an appropriate matrix $K$, to be like $|\arg (e i g(A+K))|>\frac{q \pi}{2}$, synchronisation occurs and the proposed sliding surface $e^{2}$ is asymptotically stable.

Proof. The candidate Lyapunov function is as below:

$V=\frac{1}{2} S^{T} S$

We have:

$$
\begin{gathered}
\dot{V}=S^{T} \dot{S}=S^{T}\left[D^{q} E(t)-(A+K) E(t)\right]=S^{T}[A E(t)+B g(Y)- \\
-B g(X)+H(Y, t)-H(X, t)+K E(t)+B g(X)-B g(Y)-r S- \\
\left.-\rho_{1} \gamma_{1} \operatorname{sign}(S)-\rho_{2} \gamma_{2} \operatorname{sign}(S)-A E(t)-K E(t)\right] \leq \\
\quad \leq-r\|S\|^{2}-\left(1+\rho_{1}\right) \gamma_{1}\|S\|+\left(1-\rho_{2}\right) \gamma_{2}\|S\|<0
\end{gathered}
$$

Therefore, a Lyapunov function has been found that satisfies the conditions of the Lyapunov theorem $(V>0, \dot{V}<0)$. The calculated Control law (22) is asymptotically stable.

Designing a sliding mode controller for two separate, fractional-order uncertain chaotic system in the presence of external noise
The goal is the synchronisation of the two separate fractional-order chaotic systems. Therefore, we rewrite the master system in the presence of uncertainty and external noise as below.

$D^{q_{1}} X(t)=A_{1} X(t)+B_{1} g(X)+H(X, t)$

where $H(X, t)=\Delta f\left(x_{1}, x_{2}, x_{3}\right)+d(t)$. In addition, the slave system is as follows:

$D^{q_{2}} Y(t)=A_{2} Y(t)+B_{2} g(Y)+H(Y, t)+U(t)$

where $H(Y, t)=\Delta f\left(y_{1}, y_{2}, y_{3}\right)+d(t)$.

Using Equations (25) and (26), we define the error signal as:

$$
\begin{aligned}
D^{q_{2}} Y(t)-D^{q_{1}} X=A_{2} Y(t) & +B_{2} g(Y)+H(Y, t)+U(t)- \\
& -A_{1} X(t)-B_{1} g(X)-H(X, t) .
\end{aligned}
$$

By adding $D^{q_{2}} X(t)-D^{q_{2}} X(t)$ and $A_{2} X(t)-A_{2} X(t)$ expressions to the second side of the equation (27), we will have:

$D^{q_{2}} Y(t)-D^{q_{1}} X=A_{2} Y(t)+B_{2} g(Y)+H(Y, t)+U(t)-A_{1} X(t)-$
$-B_{1} g(X)-H(X, t)+D^{q_{2}} X(t)-D^{q_{2}} X(t)+A_{2} X(t)-A_{2} X(t)$

It can be concluded that:

$$
\begin{array}{r}
D^{q_{2}} E(t)=A_{2} E(t)+B_{2} g(Y)+H(Y, t)+U(t)+\left(A_{2} X(t)-\right. \\
\left.-A_{1} X(t)\right)+\left(D^{q_{1}} X(t)-D^{q_{2}} X(t)\right)-B_{1} g(X)-H(X, t)
\end{array}
$$

where $D^{q_{2}} E(t)=D^{q_{2}} Y(t)-D^{q_{2}} X(t)$ and $A_{2} E(t)=A_{2} Y(t)-$ $A_{2} X(t)$.

As a choice, a new fraction-integer integral switching surface $S(t)$ is selected as follows:

$S(t)=D^{q_{2}-1} E(t)-\int_{0}^{t}\left(A_{2}+K\right) E(\tau) d \tau$

The proposed control law for the two separate fractional-order chaotic systems is as follows

$$
\begin{aligned}
U(t) & =K E(t)+B_{1} g(X)-B_{2} g(Y)-\left(A_{2} X(t)-A_{1} X(t)\right)- \\
& -\left(D^{q_{1}} X(t)-D^{q_{2}} X(t)\right)- \\
& -\left(r S+\rho_{1} \gamma_{1} \operatorname{sign}(S)+\rho_{2} \gamma_{2} \operatorname{sign}(S)\right)
\end{aligned}
$$

Theorem 3. The trajectories of the system in Equation (26) tend to those of the master system in Equation (25) if the sliding surface and control law are selected as Equations (30) and (31), respectively, where constants of gain control are adopted as $r>0, \rho_{1}>-1, \rho_{2}>1$, and an appropriate matrix $K$ is selected such

that. $\left|\arg \left(e i g\left(A_{2}+K\right)\right)\right|>\frac{q_{2} \pi}{2}$.

Proof. Choosing the candidate Lyapunov function as

$V=\frac{1}{2} S^{T} S$

We have 


$$
\begin{aligned}
\dot{V} & =S^{T} \dot{S}=S^{T}\left[D^{q_{2}} E(t)-\left(A_{2}+K\right) E(t)\right]=S^{T}\left[A_{2} E(t)+B_{2} g(Y)-\right. \\
& -B_{1} g(X)+H(Y, t)-H(X, t)+\left(A_{2} X(t)-A_{1} X(t)\right)+ \\
& +\left(D^{q_{1}} X(t)-D^{q_{2}} X(t)\right)+K E(t)+B_{1} g(X)-B_{2} g(Y)- \\
& -\left(A_{2} X(t)-A_{1} X(t)\right)-\left(D^{q_{1}} X(t)-D^{q_{2}} X(t)\right)- \\
- & \left.r S-\rho_{1} \gamma_{1} \operatorname{sign}(S)-\rho_{2} \gamma_{2} \operatorname{sign}(S)-A_{2} E(t)-K E(t)\right] \leq \\
& \leq-\eta\|S\|^{2}-\left(1+\rho_{1}\right) \gamma_{1}\|S\|+\left(1-\rho_{2}\right) \gamma_{2}\|S\|<0
\end{aligned}
$$

Since the Lyapunov function is positive and its derivation is negative, asymptotic stability of the controller is only achieved when the controller's gains are selected appropriately, i.e., $r>0, \rho_{1}>-1$, and $\rho_{2}>1$.

\section{SIMULATION RESULT}

In this section, two clear examples are presented based on the proposed sliding mode controller. The output results support the theoretical results.

Example 1. The fractional-order Lorenz chaotic system is a subsidiary of the unified fractional-order chaotic systems in Equation (5) $(\alpha=0)$. Chaotic behavior has been shown without uncertainty, external noise, and input in Fig. 1. Here, we have considered Master System (18) in the presence of uncertainty:

$\Delta f\left(x_{1}, x_{2}, x_{3}\right)=0.3\left[\sin \left(\pi x_{1}\right) \sin \left(\pi x_{2}\right) \cos \left(2 \pi x_{3}\right)\right.$,

$$
\left.\cos \left(\pi x_{1}\right) \cos \left(\pi x_{2}\right) \sin \left(2 \pi x_{3}\right), \sin ^{2}\left(\pi x_{1}\right) \sin \left(\pi x_{3}\right)\right]^{T}
$$

and external noise $d(t)=0.3[\cos (3 t), \cos (4 t), \cos (6 t)]^{T}$, and Slave System (20) in the presence of uncertainty:

$$
\begin{gathered}
\Delta f\left(y_{1}, y_{2}, y_{3}\right)=0.25\left[\cos \left(\pi y_{1}\right) \cos \left(\pi y_{2}\right) \cos \left(3 \pi y_{3}\right),\right. \\
\left.\sin \left(\pi y_{1}\right) \sin ^{2}\left(2 \pi y_{3}\right), \sin \left(\pi y_{1}\right) \cos ^{2}\left(2 \pi y_{2}\right)\right]^{T}
\end{gathered}
$$

and external noise $d(t)=0.25[\sin (3 t), \sin (4 t), \sin (7 t)]^{T}$. In addition, we have $\|H(X, t)\| \leq 0.6$ and $\|H(Y, t)\| \leq 0.5$.

For simulation results, we have suggested:
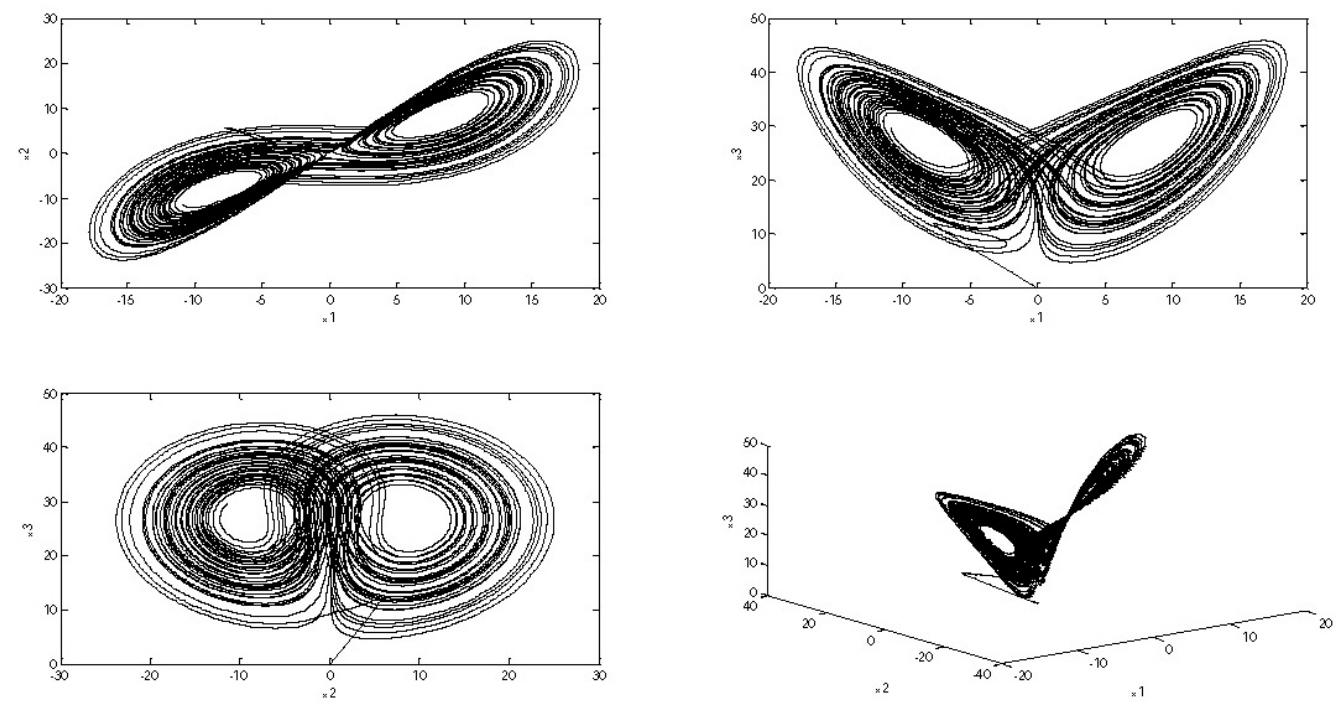

Fig 1. Phase diagram of the Lorenz system with fractional order $q=[0.995,0.995,0.995]$. 


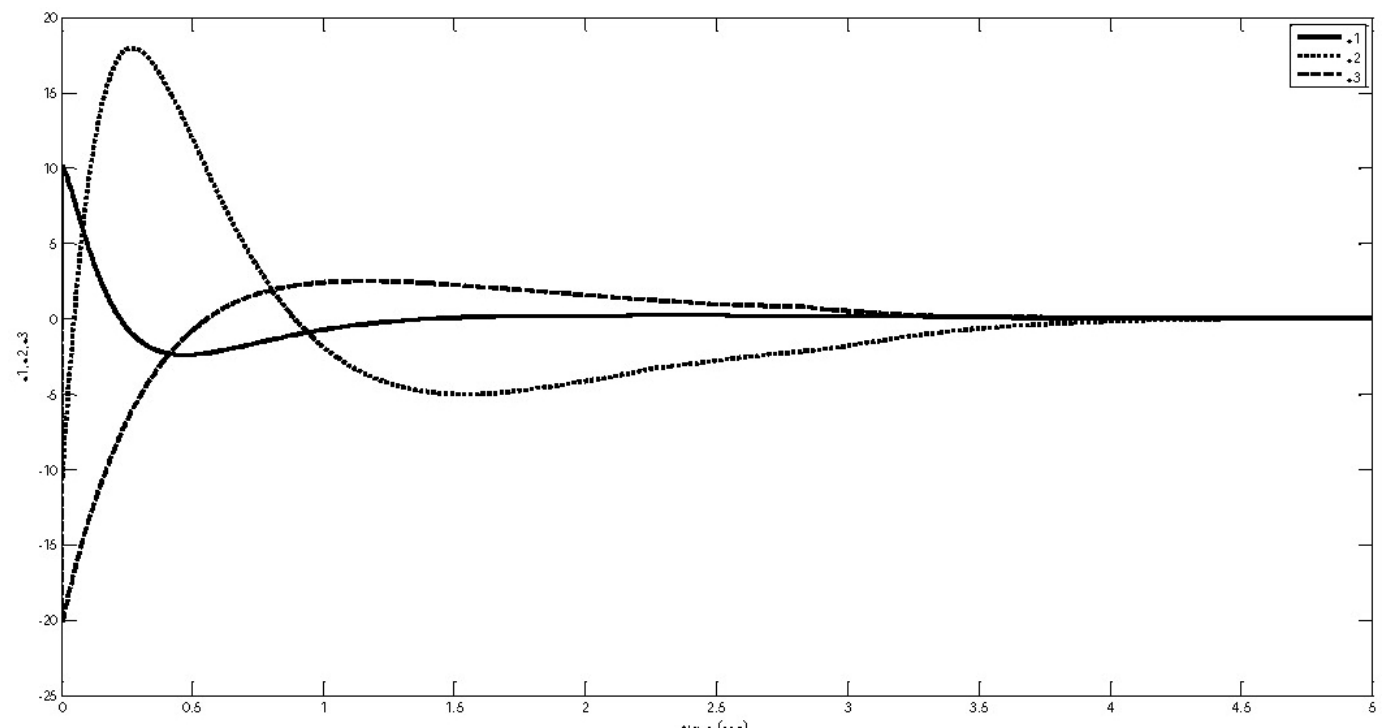

Fig 2. Time of synchronisation error states.
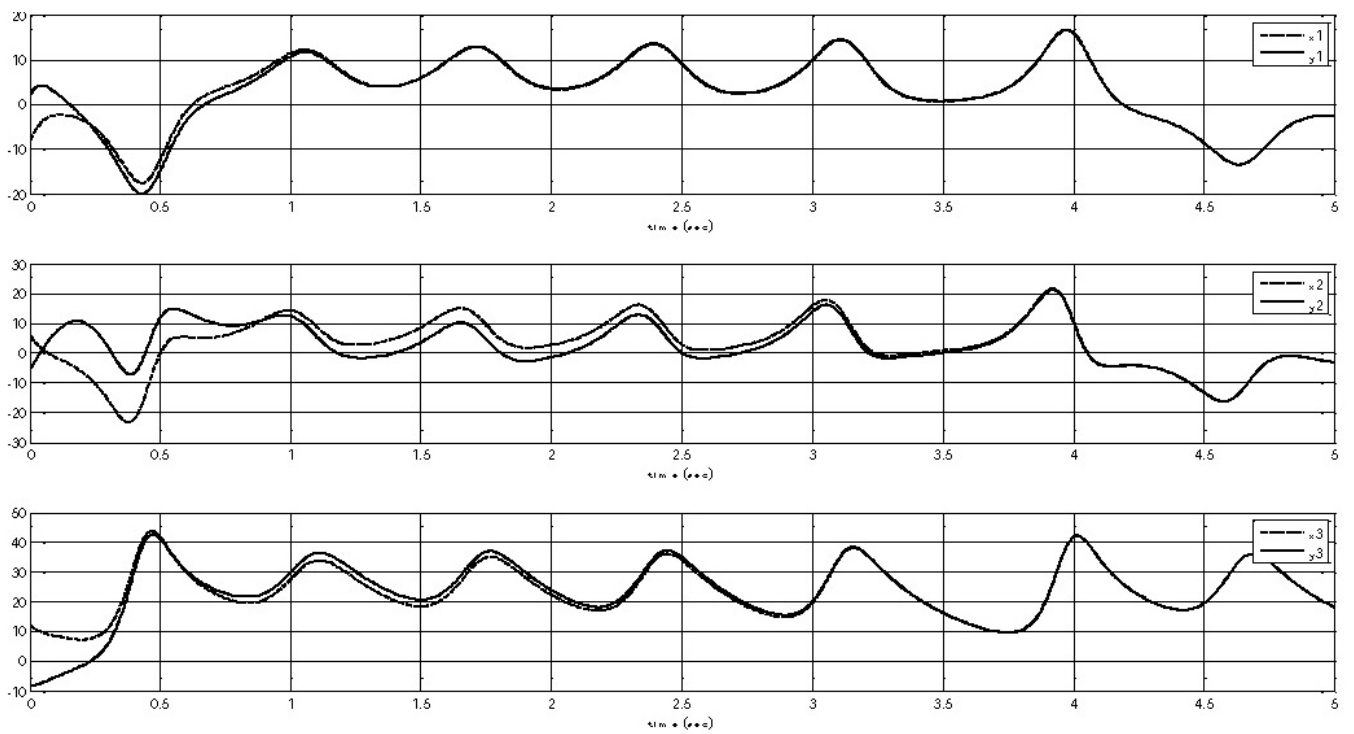

Fig 3. Result of synchronisation of the state variables.
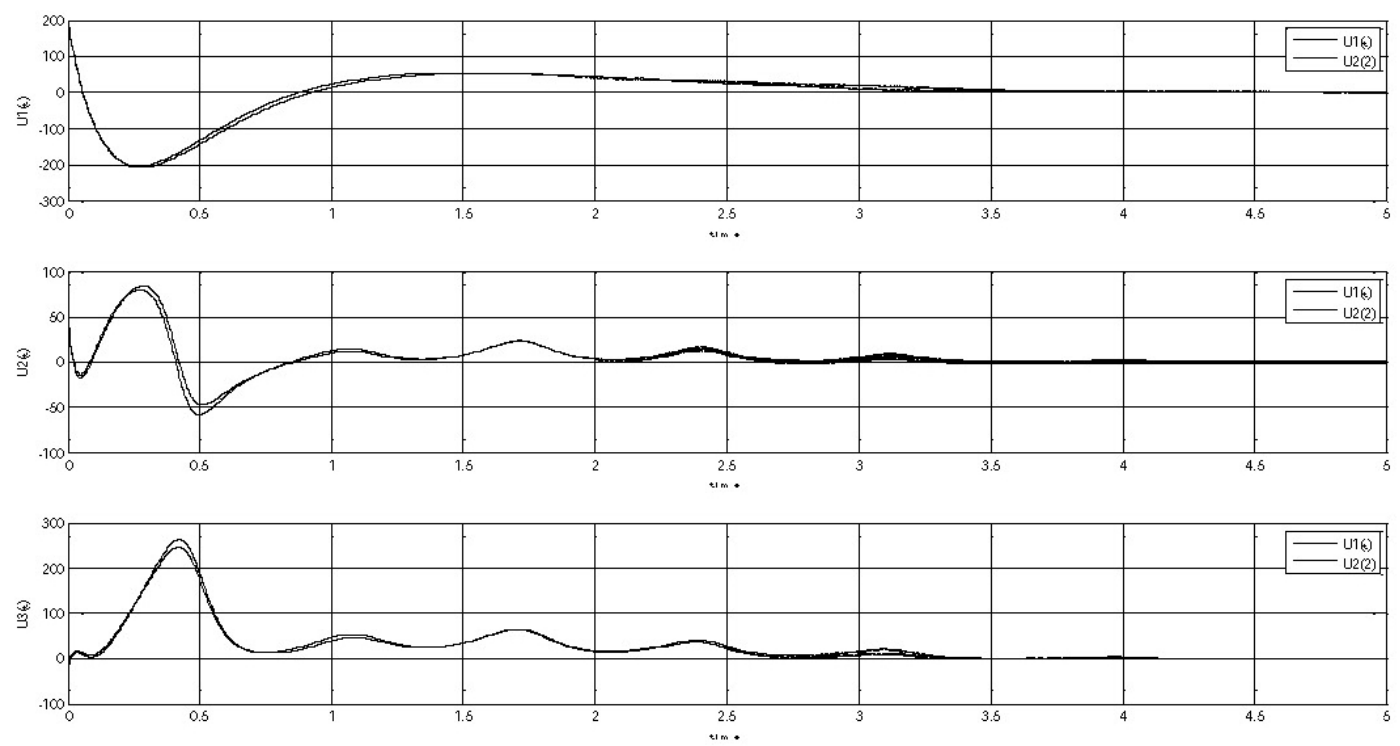

Fig 4. The evolutions of control law (22) for $U_{1}(t)$ where $\left[r=1, \rho_{1}=1, \rho_{2}=1.2\right]$ and $U_{2}(t)$ where $\left[r=1.2, \rho_{1}=1.2\right.$, $\left.\rho_{2}=1.5\right]$.

$\sin \left(\pi x_{1}\right) \cos \left(4 \pi x_{2}\right) \sin \left(3 \pi x_{3}\right)$,

$\left.\cos \left(4 \pi x_{1}\right) \cos \left(3 \pi x_{2}\right) \cos \left(2 \pi x_{3}\right)\right]^{T}$ and external noise $d(t)=0.4[\sin (6 t), \sin (4 t), \sin (2 t)]^{T}$, and System (26) as the slave system in the presence of uncertainty: 
$\Delta f\left(y_{1}, y_{2}, y_{3}\right)=0.35\left[\cos \left(3 \pi y_{1}\right) \cos \left(2 \pi y_{2}\right) \sin \left(\pi y_{3}\right)\right.$,

$$
\begin{aligned}
& \sin \left(\pi y_{1}\right) \sin \left(5 \pi y_{2}\right) \sin \left(2 \pi y_{3}\right), \\
& \left.\cos \left(\pi y_{1}\right) \sin \left(2 \pi y_{2}\right) \sin \left(4 \pi y_{3}\right)\right]^{T}
\end{aligned}
$$

and external noise $d(t)=0.35[\cos (4 t), \cos (4 t), \cos (2 t)]^{T}$.

In addition, we have $\|H(X, t)\| \leq 0.8$ and $\|H(Y, t)\| \leq 0.7$. For simulation results, we have suggested

$q_{1}=[0.95,0.95,0.95]$,

$\left[{ }_{0} D_{t}^{-0.05} x_{1}(0) \quad{ }_{0} D_{t}^{-0.05} x_{2}(0) \quad{ }_{0} D_{t}^{-0.05} x_{3}(0)\right]=[-9,-5,14]$,

and $q_{2}=[0.993,0.993,0.993]$

$\left.{ }_{0} D_{t}^{-0.007} y_{1}(0) \quad{ }_{0} D_{t}^{-0.007} y_{2}(0) \quad{ }_{0} D_{t}^{-0.007} y_{3}(0)\right]=[8,9,-9]$

for the fractional-order and initial conditions of the master and slave systems, respectively. We choose

$K=\left[\begin{array}{ccc}-9 & -9 & -2 \\ -16 & -16 & -15 \\ -1 & 0 & 0\end{array}\right]$
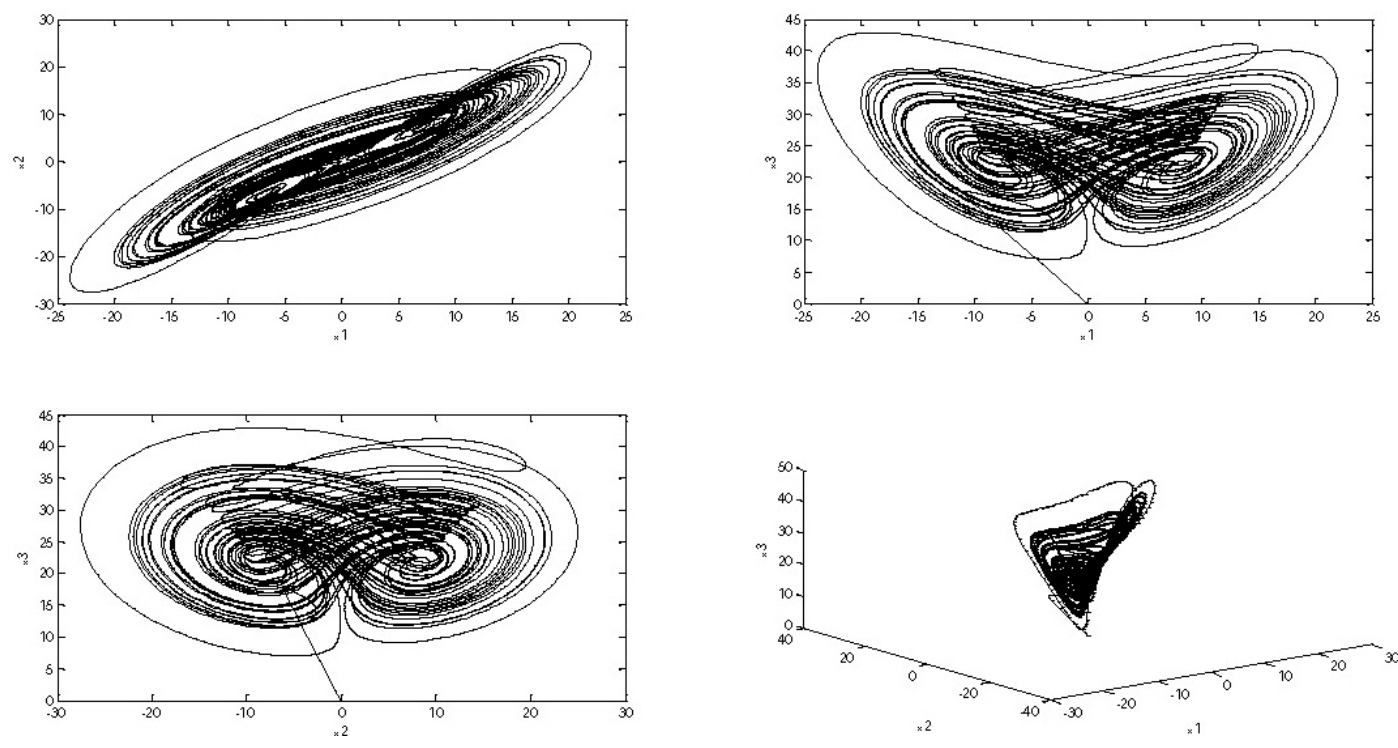

Fig 5. Phase diagram of Chen system with fractional order $q=[0.95,0.95,0.95]$.

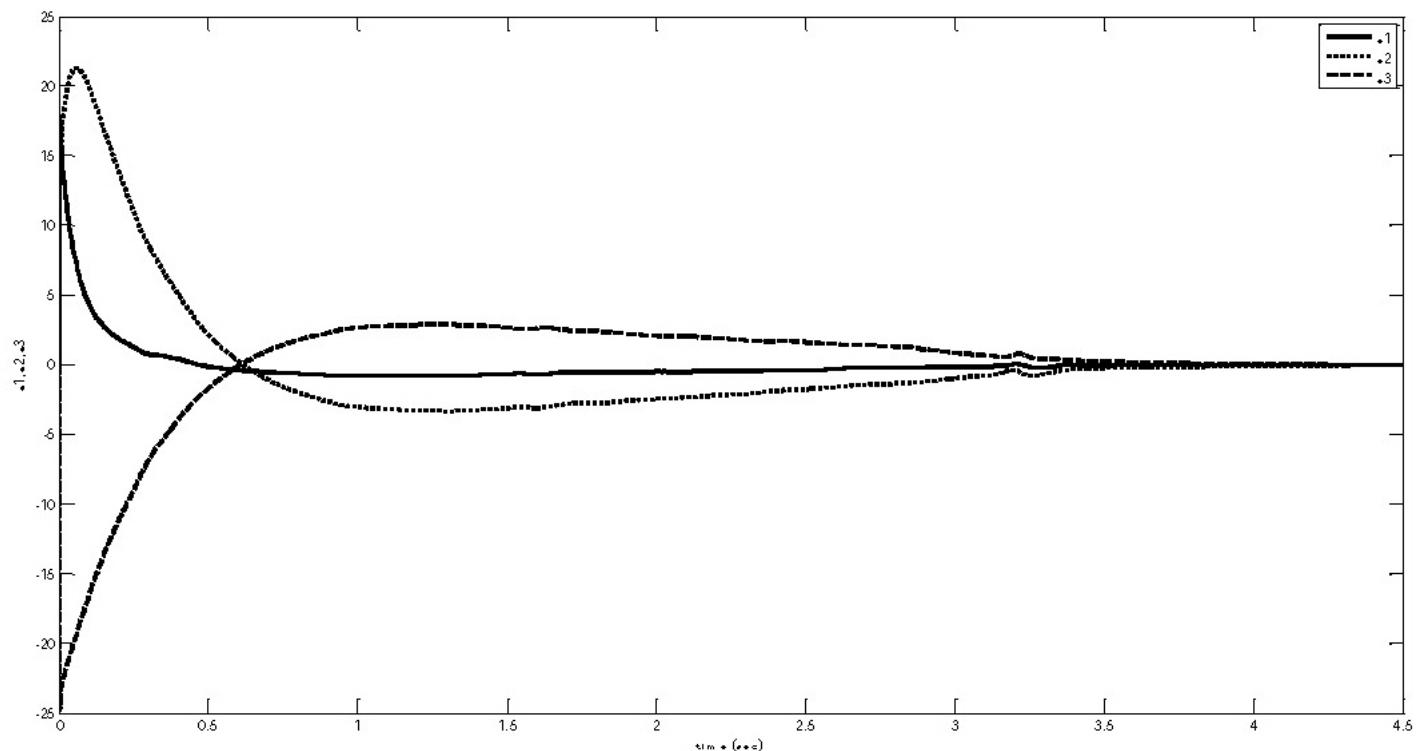

Fig 6. Time of synchronisation of error states. 

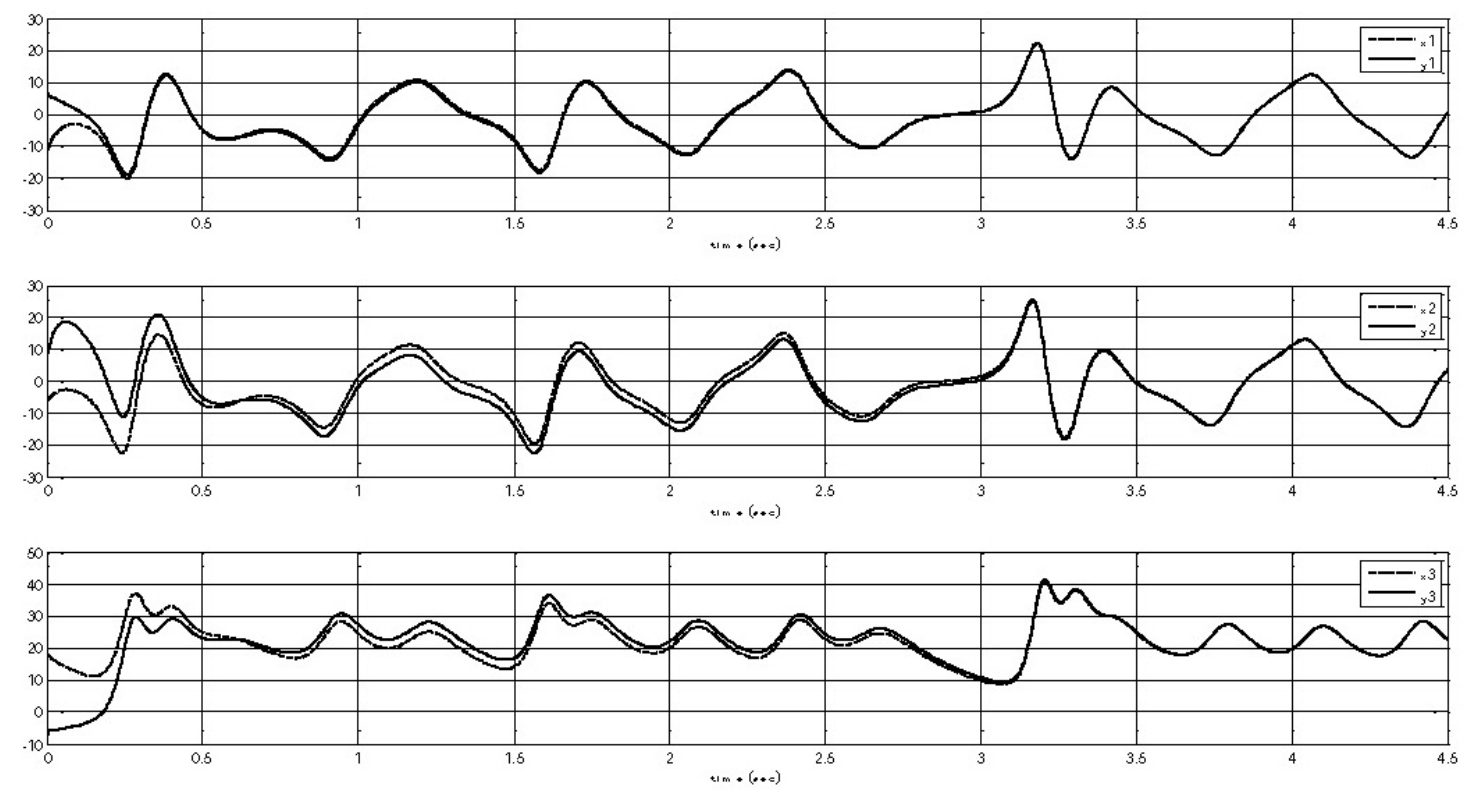

Fig 7. Result of synchronisation of the state variables.
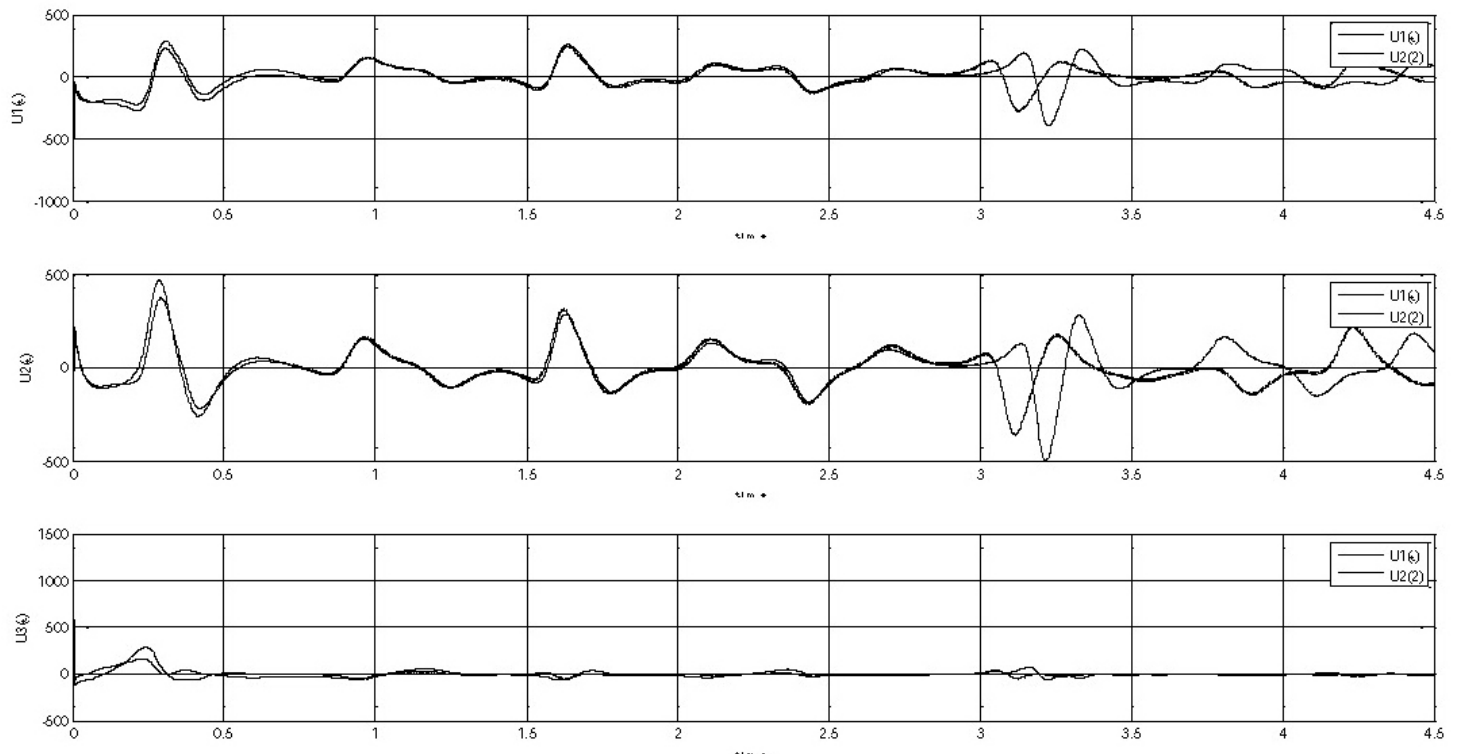

Fig 8. The evolutions of control law (31) for $U_{1}(t)$ where $[r=0.9$, $\left.\rho_{1}=1, \rho_{2}=1.1\right]$ and $U_{2}(t)$ where $\left[r=3, \quad \rho_{1}=3\right.$, $\left.\rho_{2}=3.5\right]$.

tiveness in the elimination of uncertainty and external noise. In addition, a decline in the chattering phenomenon is promoted through the convergence response effectuated by increasing the control parameters, as can be observed in the examples.

\section{REFERENCES}

Aghababa, M. P. (2014). Chaotic behavior in fractional-order horizontal platform systems and its suppression using a fractional finite-time control strategy. J. Mech. Sci. Technol., 28 (5), 1875-1880.

Aghababa, M. P., Borjkhani, M. (2014). Chaotic fractional-order model for muscular blood vessel and its control via fractional control scheme. Complexity, 20 (2), 37-46.

Airaudo, M., Zanna, L. F. (2012). Interest rate rules, endogenous cycles, and chaotic dynamics in open economies. J. Econ. Dyn. Control, 36, 1566-584.

Banerjee, S., Mukhopadhyay, S., Amberto Rondoni L. (2012). Multi-image encryption based on synchronization of chaotic lasers and iris authentication. Opt. Laser Eng., 50 (7), 950-957.

Chai, Y. I., Chen, L., Wu, R., Dai, J. (2013). Q-S synchronization of the fractional-order unified system. PRAMANA - Journal of Physics, 80 (3), 449-461.
Cortes, F., Elejabarrieta, M. J. (2007). Finite element formulations for transient dynamic analysis in structural systems with viscoelastic treatments containing fractional derivative models. Int. J. Numer. Meth. Eng., 69, 2173-2195.

Faieghi, M. R., Delavari, H. (2012). Chaos in fractional-order Genesio-Tesi system and its synchronization. Commun. Nonlinear Sci. Numer. Simulat., 17 (2), 731-741.

Gao, W. (2012). Study on statistical properties of chaotic laser light. Phys. Lett. A, 331 (5), 292-297.

Hernandez, R. T., Ramirez, V., Silva, G. I., Diwekar, U. M. (2014). A fractional calculus approach to the dynamic optimization of biological reactive systems. Part I: Fractional models for biological reactions. Chemical Engineering Science, 117, 217-228.

Hosseinalipour, S. M., Tohidi, A., Shokrpour, M., Nouri, N. M. (2013). Introduction of a chaotic dough mixer. Part A: mathematical modeling and numerical simulation, J. Mech. Sci. Technol., 27 (5), 1329-1339.

Kareem, S. O., Ojo, K. S., Njah, A. N. (2012). Function projective synchronization of identical and non-identical modified finance and ShimizuMorioka systems. PRAMANA - Journal of Physics, 79 (1), 71-79.

Kupka, J. (2014). Some chaotic and mixing properties of fuzzified dynamical systems, Inf. Sci., 279, 642-653. 
Li, R., Chen, W. (2014). Lyapunov-based fractional-order controller design to synchronize a class of fractional-order chaotic systems. Nonlinear Dyn., 76 (1), 785-795.

Li, C., Tong, Y. (2013). Adaptive control and synchronization of a fractional-order chaotic system, PRAMANA - Journal of Physics, 80 (4), 583-592.

Matignon, D. (1996). Stability results for fractional differential equations with applications to control processing. In: IEEE-SMC Proceedings of the Computational Engineering in Systems and Application Multiconference. IMACS, Lille, France, Vol. 2, pp. 963-968.

Monje, C. A., Chen, Y., Vinagre, B. M., Xue, D., Feliu, V. (2010). Fractional-order Systems and Controls. Springer. 2010. 415 pp.

Muthukumar, P., Balasubramaniam, P., Ratnavelu, K. (2015). Fast projective synchronization of fractional order chaotic and reverse chaotic systems with its application to an affine affine cipher using date of birth (DOB). Nonlinear Dynamics, 80 (4), 1883-1897.

Padula, F., Visioli, A. (2014). Inversion-based feedforward and reference signal design for fractional constrained control systems. Automatica, 50 (8), 2169-2178.

Pai, M. C. (2014). Global synchronization of uncertain chaotic systems via discrete-time sliding mode control. Appl. Math. Comput., 227 (15), 663-671.

Pakzad, M. A., Pakzad, S., Nekoui, M. A. (2013). Stability analysis of time-delayed linear fractional-order systems. Int. J. Control Autom. Syst., 11 (3), 519-525

Pan, I., Korre, A., Das, S., Durucan, S. (2012). Chaos suppression in a fractional order financial system using intelligent regrouping PSO based fractional fuzzy control policy in the presence of fractional Gaussian noise. Nonlinear Dyn., 70 (4), 2445-2461.

Received 13 December 2014

Accepted in the final form 13 August 2016
Provata, A., Katsaloulis, P., Verganelakis, D. A. (2012). Dynamics of chaotic maps for modelling the multifractal spectrum of human brain Diffusion Tensor Images. Chaos Solitons Fractals, 45, 174-180.

Sarbaz, Y., Towhidkhah, F., Jafari, A., Gharibzadeh, S. (2012). Do the chaotic features of gait change in Parkinson's disease? J. Theor. Biol., 307, 160-167.

Srivastava, M., Ansari, S. P., Agrawal, S. K., Das, S., Leunga Y. T. (2014). Anti-synchronization between identical and non-identical fractional-order chaotic systems using active control method. Nonlinear Dyn.,76 (2), 905-914.

Tripathy, M. C., Mondal, D., Biswas, K., Sen, S. (2015a). Design and performance study of phase-locked loop using fractional-order loop filter. Int. J. Circ. Theor. Appl., 43 (6), 776-792.

Tripathy, M. C., Mondal, D., Biswas, K., Sen, S. (2015b). Experimental studies on realization of fractional inductors and fractional-order bandpass filters. Int. J. Circ. Theor. Appl., 43 (9), 1183-1196.

Wang, J. R., Li, X. (2014). Periodic BVP for integer/fractional order nonlinear differential equations with non-instantaneous impulses. J. Appl. Math. Comput., 46 (1), 321-334.

Xiao, X., Zhou, L., Zhang, Z. (2014). Synchronization of chaotic Lur'e systems with quantized sampled-data controller. Commun. Nonlinear Sci. Numer. Simulat., 19 (6), 2039-2047.

Yin, C., Dadras, S., Zhong, S., Chen, Y. Q. (2013). Control of a novel class of fractional-order chaotic systems via adaptive sliding mode control approach. Appl. Math. Modelling, 37 (4), 2469-2483.

Zhang, L., Yan, Y. (2014). Robust synchronization of two different uncertain fractional-order chaotic systems via adaptive sliding mode control. Nonlinear Dyn., 76 (3), 1761-1767.

\section{NENOTEIKTO FRAKCIONĀLI NOZĪMĒTO HAOTISKO VIENOTO SISTĒMU ROBUSTA SINHRONIZĀCIJA}

Frakcionāli nozīmētās haotiskās vienotas sistēmās (FNHVS) ietilpst tādas sistēmas, kā Chen, Lorenz, Lu, Liu un finanšu sistēmas. Rakstā aprakstīts kontrollers slīdošā režīmā, kas sinhronizē FNHVS nenoteiktības un ārējo traucējumu klātbūtnē. Modelēšana ar MATLAB parādīja, ka piedāvātā metode samazina rezultātu nenoteiktîbu. 